\title{
Porcellidiidae of Australia (Harpacticoida, Copepoda). I. A Reassessment of the European Species of Porcellidium
}

\author{
VERNON A. HARRIS \\ 138/99 Doolong Road, Kawungan Queensland 4655, Australia \\ vaharris@bigpond.com
}

\begin{abstract}
A new species, Porcellidium rastellum, is described from NSW bringing the total number of species in that genus for Australia to seven. Unlike other Australian genera in the Porcellidiidae, Porcellidium Claus, 1860 is ill defined. Porcellidium viride (Philippi, 1840) is considered the type species to the genus, but it has never been adequately characterized. This has led to considerable disagreement on the characters that define the genus. Porcellidium viride can be identified from a species specific character shown by Brady's (1880) drawing of the male antennules. Another species, Porcellidium fimbriatum Claus, 1863, can also be identified by species specific characters shown in the more complete description by Claus (1889). This enables new specimens of these two species to be identified with a high degree of certainty. In the present study, specimens collected from Oban, Scotland, identified as $P$. viride and $P$. fimbriatum, have been used to redescribe both species in detail and select species specific characters for a diagnosis of each species. A new diagnosis for the genus Porcellidium is given, based on the characters of $P$. viride. Extensive enquiry suggests that Philippi's and Claus' type material is lost. To ensure taxonomic stability of the genus Porcellidium, a neotype of $P$. viride is designated. From this study it is shown that $P$. lecanoides Claus, 1889 and $P$. sarsi Bocquet, 1948 are junior synonyms for $P$. viride. The new diagnosis for Porcellidium excludes many of the species originally placed in that genus. Porcellidium tenuicauda Claus, 1860 and $P$. scutatum Claus, 1889 are examples of species that possess apomorphic characters excluding them from Porcellidium sensu stricto. A new genus, Porcelloides gen. nov. is proposed to take Claus' two species, as Porcelloides tenuicaudus (Claus, 1860) comb. nov., and Porcelloides scutatus (Claus, 1889) comb. nov. Keys to the known species of Porcellidium and Porcelloides are given.
\end{abstract}

KeYwords: Porcellidiidae, Porcellidium, Porcelloides.

Harris, Vernon A. 2014. Porcellidiidae of Australia (Harpacticoida, Copepoda). I. A reassessment of the European species of Porcellidium. Records of the Australian Museum 66(2): 63-110.

Considerable progress has been made in our understanding of the family Porcellidiidae from recent studies on the fauna of the West Pacific Ocean. The works of Gamô (1969), Ho (1986), S. Kim \& W. Kim (1996), Harris \& Iwasaki (1996a,b), Il-H. Kim \& H.-S. Kim, (1997) and Harris \& Iwasaki $(1997,2009)$ have described in detail 17 new species from Japan and Korea while another 23 new species have been described from Aotearoa (New Zealand) and Australia, 